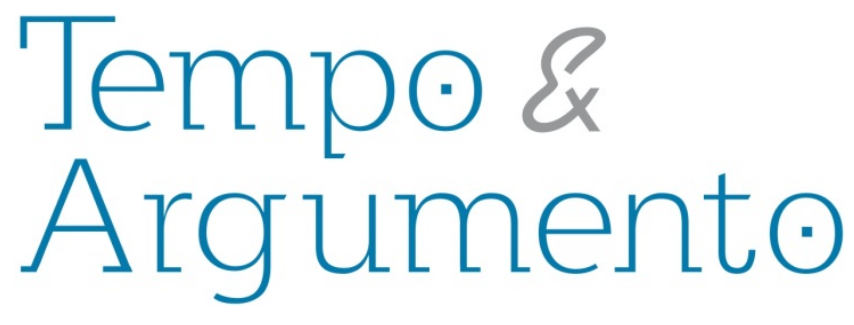

\title{
Para americano e brasileiro ver: uma memória das relações bilaterais por meio da rede social Flickr
}

\begin{abstract}
Resumo
Este trabalho investiga a memória das relações bilaterais produzida pela Embaixada dos Estados Unidos no Brasil na rede social Flickr nos primeiros meses de governo do presidente democrata Barack Obama. Analisa-se aqui o conjunto de imagens e textos de 19 postagens realizadas pela embaixada na rede no primeiro semestre de 2009. São estabelecidos elos entre a produção da memória, a conjuntura política norte-americana e mitos políticos estadunidenses, como Abraham Lincoln e John Kennedy. Também problematiza as formas lembrar e esquecer diversos eventos das relações bilaterais ao longo do século $\mathrm{XX}$ e XXI, além dos posicionamentos publicados na rede social em relação à política e à história do Brasil.
\end{abstract}

Palavras-chave: Redes sociais online; Flickr; Presidentes Estados Unidos.

\section{João Gilberto Neves Saraiva}

Mestrando no Programa de Pós-Graduação em História da Universidade Federal do Rio Grande do Norte. Brasil jgilbertons@gmail.com

\section{Para citar este artigo:}

SARAIVA, João Gilberto Neves. Para americano e brasileiro ver: uma memória das relações bilaterais através da rede social Flickr. Revista Tempo e Argumento, Florianópolis, v. 6, n. 12, p. 85 110, mai./ago. 2014.

\section{DOI: $10.5965 / 2175180306122014085$}

http://dx.doi.org/10.5965/2175180306122014085 
For showing to U.S. and Brazilian people: a memory of bilateral relations through the social network Flickr

\begin{abstract}
This paper investigates the memory of bilateral relations produced by the U.S. Embassy in Brazil on the social network Flickr in the early months of the administration of the Democrat President Barack Obama. The set of images and texts in 19 posts made by the Embassy's profile on the network in the first half of 2009 is analyzed here. It establishes connections between the production of memory, the U.S. political conjuncture, and U.S. political myths, such as Abraham Lincoln and John Kennedy. It also discusses ways of remembering and forgetting several events in bilateral relations throughout the $20^{\text {th }}$ and $21^{\text {st }}$ centuries, besides the positions published on the social network regarding Brazilian politics and history.
\end{abstract}

Keywords: Social Networks; Flickr; President - United States. 
Hoje o tempo avança a grandes passos. O acontecimento histórico, esquecido numa noite, cintila a partir do dia seguinte com o orvalho do novo e não é mais portanto um pano de fundo no relato do narrador, mas sim uma surpreendente aventura que se desenrola no segundo plano da banalidade. (KUNDERA, 1987, p. 19)

Em maio de 2013, o vice-presidente dos Estados Unidos realizou uma visita oficial de três dias ao Brasil. Da agenda de Joe Biden constaram eventos oficiais no Rio de Janeiro e Brasília, amplamente noticiados por jornais impressos, emissoras de televisão e portais de notícias brasileiros ${ }^{1}$. Entre os encontros com autoridades no Palácio do Planalto e passeios com líderes comunitários em favelas ocupadas militarmente, como a do Morro Santa Marta na Zona Sul da capital fluminense, a cobertura jornalística sublinhou pronunciamentos elogiosos do vice-presidente democrata em relação ao País e às relações bilaterais. Segundo matéria de João Fellet (2013), enquanto discursava em Brasília, Biden teria afirmado: "Vocês demonstraram ao mundo que não precisa haver uma falsa escolha entre desenvolvimento e democracia". Já sobre o futuro do continente, o vice-presidente teria projetado:

Podemos ver no futuro um continente americano de classe média, democrático, seguro, do Círculo Ártico ao Estreito de Magalhães. A questão para os Estados Unidos não é o que podemos fazer pelas Américas, mas o que podemos fazer juntos. E nenhum parceiro é tão significativo nesse empreendimento quanto o Brasil (QUERO, 2013).

Uma revisão crítica das relações bilaterais evidencia diversos contextos de tensões em função das quais os governos dos Estados Unidos agiram para que "seu parceiro mais significativo" escolhesse o desenvolvimento no lugar da democracia. Pesquisas como as de Carlos Fico (2008), James Green e Abigail Jones (2009), por exemplo, investigam a atuação, em nome da segurança e do desenvolvimento, do governo norte-americano para minar o então presidente do Brasil, eleito democraticamente, João Goulart, e seu

\footnotetext{
${ }^{1}$ Entre eles: O Globo <http://oglobo.globo.com/pais/visita-de-vice-presidente-dos-eua-brasilia-quase-vira-diada-fritura-em-programa-oficial-8549483>, Correio Braziliense <http://www.correiobraziliense.com.br/ app/galeria-de-fotos/2013/05/31/interna_galeriafotos,4533/31-5-vice-presidente-norte-americano-visita-obrasil.shtml>, O Estado de São Paulo <http://www.estadao.com.br/noticias/nacional,visita-de-biden-afavela-santa-marta-dura-40-minutos,1037231,0.htm> Acesso em 17 mar. 2014.
} 
lembradas nos discursos do vice-presidente democrata pronunciados em sua visita ao Brasil.

Este trabalho questiona essas lembranças e esquecimentos; problematiza uma memória oficial das relações bilaterais construída pelo governo democrata do presidente Barack Obama e seu vice, Joe Biden, a partir das publicações da Embaixada dos Estados Unidos no Brasil na rede social Flickr em 2009. Ao trabalhar com uma rede social na internet, pensamos que a cultura digital em que ela se insere introduziu novas formas de construção, publicação e recepção de discursos históricos. Assim, aproximamo-nos do historiador Roger Chartier ao refletir que:

A textualidade eletrônica de fato transformou a maneira de organizar as argumentações, históricas ou não, e os critérios que podem mobilizar um leitor para aceitá-las ou rejeitá-las. [...] Permite uma articulação aberta, fragmentada, relacional do raciocínio, tornada possível pela multiplicação de ligações hipertextuais (CHARTIER, 2009, p. 59).

Dentro desse universo de conexões da textualidade eletrônica, interessam-nos as apropriações, as formas de lembrar e de esquecer eventos e conjunturas históricas na produção de uma memória das relações bilaterais pela embaixada norte-americana, órgão oficial que representa os Estados Unidos e intermedeia as relações entre os dois países. Optamos por analisar as publicações no Flickr, uma rede de hospedagem e compartilhamento de fotografias lançada na internet em fevereiro de 2004, que permite aos usuários criar álbuns fotográficos que queiram ou possam compartilhar com usuários dentro e fora da rede.

O perfil da embaixada, nessa rede social ${ }^{2}$, abriga mais de cinco mil fotografias, e respectivas legendas, hiperlinks e comentários. Dentro dos limites deste trabalho, optamos pelo álbum "Relações bilaterais na história/Historical Photos of U.S.-Brazil

\footnotetext{
${ }^{2}$ O perfil da Embaixada dos Estados Unidos no Brasil no Flickr é disponível no endereço eletrônico <http://www.flickr.com/people/embaixadaeua-brasil/> Acesso em: 17 mar. 2014.
} 
Bilateral Relations"3. Disponibilizado a partir de março de 2009, o álbum faz uma recapitulação de diversos contatos oficiais entre os países nos séculos XX e XXI em 19 postagens. Assim como o título, as informações disponibilizadas são bilíngues português e inglês - para atender ao público dos dois países.

A partir da perspectiva de Ana Maria Mauad (2008, p. 14), convertemos esses conjuntos de imagens e textos em fontes, pensando-os como práticas sociais portadoras de múltiplos sentidos históricos. Neste sentido, os álbuns fotográficos são produtos de escolhas que produzem o que Mauad (1996, p. 77) denomina de "narrativas que engendram memórias". Assim, entendemos ser pertinente inquirir as narrativas das relações bilaterais criadas no álbum do Flickr da embaixada, pensando-as como memória social construída. O historiador Peter Burke problematiza a produção da memória. Para ele:

São os indivíduos que lembram, no sentido literal, físico, mas são os grupos sociais que determinam aquilo que é "memorável", e também a maneira como será lembrado. Os indivíduos se identificam com os acontecimentos públicos de importância para seu grupo. "Lembram" muito do que não viveram diretamente. [...] Daí, pode-se descrever a memória como uma reconstrução do passado (BURKE, 2000, p. 70).

Assim, na produção dessa memória social, o lembrar e o esquecer estão muito longe de serem atividades inocentes. O conjunto das postagens na rede social pode ser pensado, então, como uma reconstrução de um passado através de diversos princípios de seleção, interpretação e distorção dos fenômenos.

Os dados da embaixada dos Estados Unidos no Flickr informam que a conta foi criada em março de 2009. Dois meses antes, os democratas Barack Obama e Joe Biden assumiram seus postos, respectivamente, como presidente e vice-presidente, depois de oito anos de governo de George W. Bush. A criação do álbum investigado data da mesma época; foi um dos primeiroscriados na conta da embaixada.Ao longo dos quatro meses seguintes foi recebendo novas publicações. Em síntese, ele monta uma série histórica das relações entre os dois países no recorte temporal que vai da metade dos anos 1940 até a

3 O álbum em questão pode ser acessado através do sítio eletrônico <http://www.flickr.com/photos/embaixadaeua-brasil/sets/72157615306643483/> Acesso em 17 mar. 2014. 
primeira década de século XXI. Dividindo-o por décadas, temos dez publicações - quase metade do álbum - dos anos 2000, uma da década de 1970, cinco da década de 1960, uma dos anos 1940 e outra, da década 1930. A organização das postagens no Flickr monta uma narrativa visual em modelo presente-passado-presente, e inicia com o encontro de Lula e Obama, depois recua no tempo passando por George Bush, Jimmy Carter, John Kennedy e Franklin Roosevelt, para depois retomar as ações do governo Obama. As onze primeiras fotos do álbum que formam essa linha temporal foram postadas na primeira quinzena de março; as oito demais tratam de encontros nos primeiros meses do novo governo democrata e foram postadas entre abril e maio.

A historiadora Ana Maria Mauad (1996, p. 76) destaca as séries fotográficas como um conjunto de escolhas possíveis de acordo com uma visão de mundo específica. Uma análise desse conjunto evidencia a produção de uma memória das relações bilaterais ligadas ao partido democrata. Das 19 publicações, apenas duas focam em figuras do partido republicano: uma delas é do presidente George Bush com Lula, em 2007; a outra, da então secretária de Estado, Condoleezza Rice, e com o ministro das relações exteriores, Celso Amorim, durante uma coletiva de imprensa em 2008. Todas as demais são de governantes, assessores e políticos democratas em encontros mundiais, regionais ou bilaterais com autoridades brasileiras ou da atuação da embaixada norte-americana no País a partir da chegada de Obama ao poder. É pertinente a consideração de Cecília Azevedo (2004, p. 2), de que a visão da política externa norte-americana como lugar simbólico de consenso bipartidário é um mito. O Flickr da embaixada estadunidense aponta nesse sentido, ou seja, a política externa é um campo de disputas em que democratas e republicanos se enfrentam ocupando espaços, estabelecendo discursos e produzindo memórias. 


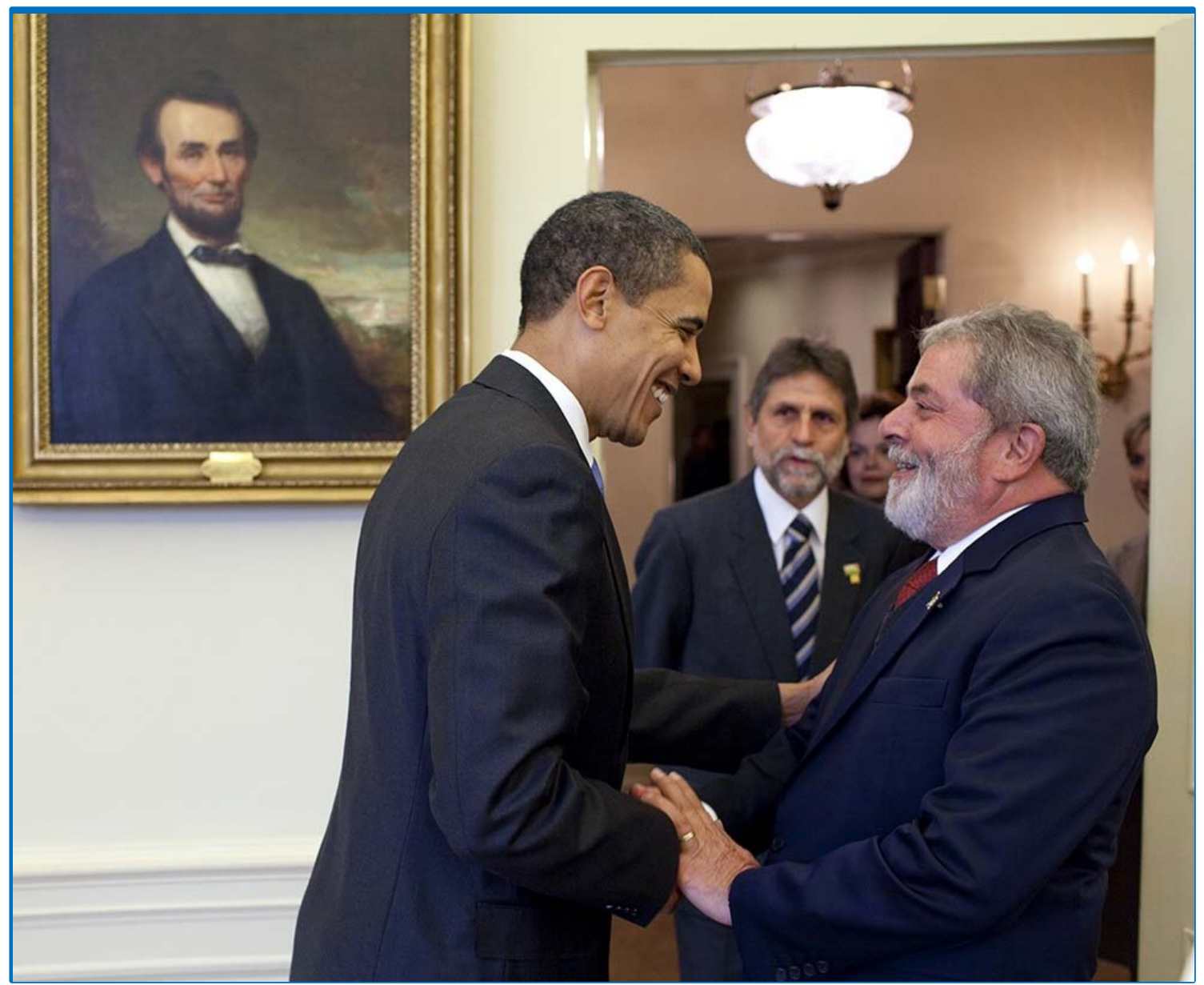

Imagem 1. O cumprimento de Barack Obama ao então presidente do Brasil, Luiz Inácio Lula da Silva.

A primeira fotografia que compõe o álbum é também sua capa; trata-se de um encontro presidencial entre Barack Obama e o brasileiro Luiz Inácio Lula da Silva. Nela imagem 1 -, os presidentes sorriem enquanto se apertam as mãos cordialmente em um dos salões da Casa Branca. Em segundo plano estão outras pessoas, como o então embaixador do Brasil nos Estados Unidos, Antônio Patriota, e a ministra-chefe da Casa Civil, Dilma Rousseff. No primeiro plano, acima dos presidentes está a única figura da composição que tem seu olhar em direção ao fotógrafo, o quadro do ex-presidente Abraham Lincoln, um dos mais fortes mitos do panteão político norte-americano. $\mathrm{O}$ historiador Raoul Girardet (1987, p. 13) aponta o mito político, entre outros aspectos,

${ }^{4}$ A fotografia é de autoria de Pete Souza e foi produzida na Casa Branca em 14 de março de 2009. Disponível no Flickr da embaixada em <http://www.flickr.com/photos/embaixadaeuabrasil/3354935802/in/set-72157615306643483/>. Acesso em: 17 mar. 2014. Todas as imagens utilizadas no trabalho possuem autorização para reprodução integral para objetivos sem fins lucrativos. 
enquanto fabulação sobre o real, dotado de uma narrativa legendária capaz de ser mobilizado e que possui uma função explicativa. Neste sentido, o quadro de Lincoln ultrapassa a rememoração da vitória na Guerra de Secessão (1861-1865), que manteve a unidade do país e a aprovação da $13^{\mathrm{a}}$ emenda constitucional (1865), que tornou ilegal a escravidão nos Estados Unidos, e adquire um alto valor mítico capaz de ser movido. A mobilização utilizada na fotografia, que associa Abraham Lincoln enquanto símbolo de liberdade a Barack Obama, o primeiro presidente negro do país, é recorrente ${ }^{5}$. Na memória social construída a partir do Flickr, o mítico $16^{\circ}$ presidente investe de valor as ações de Barack Obama, enquanto supervisiona a boa relação entre o recém-instalado governo dos Estados Unidos e o do Brasil.

Nessa mesma postagem, o siteda embaixada disponibilizou uma publicação do blog oficial Casa Branca em inglês, escrita por Jesse Lee, um dos responsáveis pela mídia digital do governo Obama. O jornalista inicia o texto fazendo uma avaliação geral do encontro entre os presidentes:

Chamando a si mesmo "um grande admirador do líder progressista e voltado para o futuro que o presidente Lula tem se mostrado", o presidente Obama abriu a coletiva de imprensa, esta tarde, após uma reunião entre os dois chefes de Estado. O presidente Lula descreveu os temas abordados no encontro, da contenção da crise financeira global para enfrentar o desemprego em todo o mundo que resulta dela, até o desenvolvimento da África e América Latina (LEE, 2009a) ${ }^{6}$.

O texto tem em vista apresentar um encontro cordial de líderes que se admiram mutuamente. A postagem no blog do recém-empossado governo democrata coloca Lula e Obama como aliados que debatem temas de relevância global entre si e com a imprensa.

\footnotetext{
${ }^{5}$ É sintomática, neste sentido, a cerimônia de posse de Barack Obama ocorrida meses antes do encontro com Lula em Washington. Segundo matéria do jornal americano The New York Times, ele utiliza a mesma bíblia sobre a qual Abraham Lincoln, em sua posse em 1861, fez seu juramento. Disponível em $<$ http://thecaucus.blogs.nytimes.com/2008/12/23/obama-to-take-oath-on-same-bible-aslincoln/?_php=true\&_type=blogs\&_r=0> Acesso em: 17 mar. 2014.

${ }^{6}$ Todas as citações em inglês foram traduzidas pelo autor; o trecho original em inglês segue em nota de rodapé:"Calling himself "a great admirer of the progressive, forward-looking leadership that President Lula has shown," President Obama opened up a joint press availability this afternoon after a meeting between the two heads of state. President Lula described the topics covered in the meeting, from stemming the global financial crisis, to addressing the unemployment around the world that results from it, to development in Africa and Latin America".
} 
A partir dos dados informados nessa página, temos que quase 2.800 usuários a visualizaram e que cinco adicionaram a sua sessão de favoritos - esta é a publicação do álbum com maior número nos dois quesitos. Isto se deve, em parte, ao fato de ser ela a capa do álbum, a imagem através da qual o usuário acessa as demais publicações, mas utilizada também como estratégia de divulgação dentro da rede.

A página informa que a embaixada disponibilizou a fotografia nos grupos “USA/Brazil”, “Brasil/Brazil” e "Brasília/DF” em grupos temáticos de imagens, já acessados por mais de 13 mil usuários. Dessa forma, definiu o encontro de Lula e Obama como imagem central da memória das relações bilaterais e ampliou a circulação dessa fotografia na rede social.

A próxima postagem da série - a imagem 2 - é também um encontro entre presidentes; dessa vez, Luiz Inácio Lula e George W. Bush. Ao contrário da fotografia anterior, os presidentes não aparentam um clima cordial. No lugar do aperto cordial de mãos, um abraço frio e certo distanciamento entre eles. No segundo plano não há pessoas, nem há qualquer ponto de referência que possa sinalizar o local onde está sendo realizado o encontro. A legenda da publicação se limita a dizer que é em São Paulo, sem fornecer qualquer outra informação detalhada, nem ao menos se se trata da cidade ou do estado. Enquanto a primeira fotografia destaca uma união amigável, cercada da simbologia política norte-americana, a segunda foi produzida em um ângulo incômodo, em que as figuras se opõem enquanto se abraçam.

A terceira publicação da série, assim como a anterior, nos remete ao governo republicano de George Bush. A legenda informa que se trata de uma entrevista à qual estavam presentes a secretária de estado Condoleezza Rice, e Celso Amorim, então ministro das relações exteriores do governo Lula $^{7}$. A legenda carece de informações precisas; como a da publicação anterior, não precisa em que lugar do Brasil estava ocorrendo a coletiva de imprensa, resumindo-se a informar a data (13 de março de 2008). Assim como na fotografia anterior, as pessoas estão sérias e não se entreolham. A 
secretária de Estado ajusta o seu fone no ouvido, enquanto o ministro brasileiro parece escutar de braços cruzados uma pergunta. A página também não faz nessas duas imagens o mesmo investimento em divulgação da primeira postada; não as inseriu em nenhum grupo do Flickr. As publicações receberam, respectivamente, até então, 623 e 346 visualizações. Nenhum usuário adicionou qualquer uma das duas como favoritas.

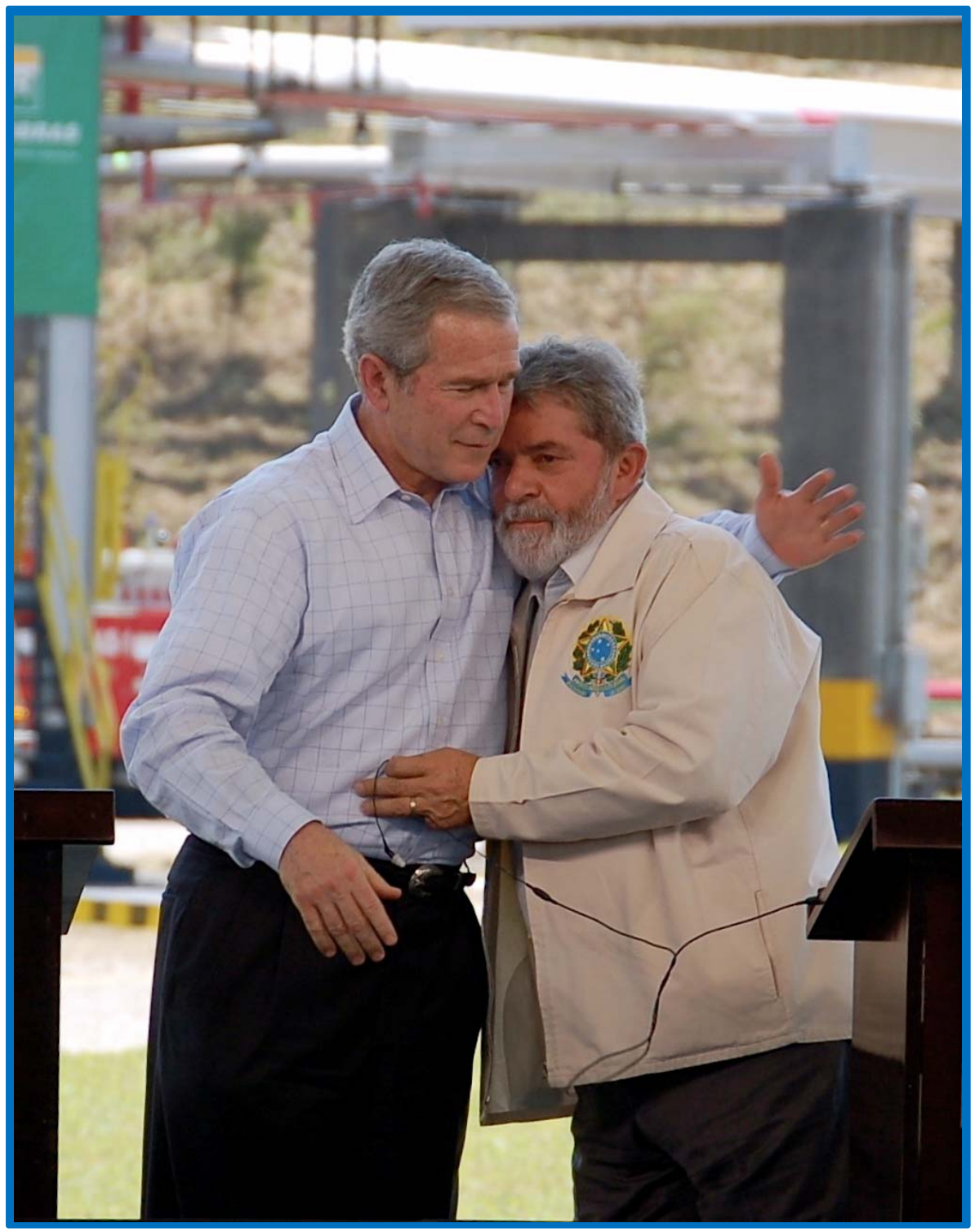

Imagem 2. O abraço de George W. Bush e Lula em São Paulo. ${ }^{8}$

\footnotetext{
${ }^{8}$ Não se identifica autor; foi fotografada em 9 de março de 2007, em São Paulo. Ela pertence ao acervo da Embaixada dos Estados Unidos no Brasil. Disponível em <http://www.flickr.com/photos/embaixadaeuabrasil/3359263103/in/set-72157615306643483/> Acesso em: 17 mar. 2014.
} 
Não acreditamos que a escolha dessas fotos, um tanto incômodas para o álbum digital sobre a história das relações bilaterais, tenha sido feita por acaso. Em se tratando de encontros entre autoridades de alto escalão da política mundial, os eventos das duas publicações tiveram uma grande cobertura televisiva e fotográfica, que criou um universo de imagens disponíveis para uso. Os responsáveis pela conta da embaixada na rede social poderiam também ter "esquecido" os encontros entre o governo Lula e o de George W. Bush, como fizeram com os que aconteceram entre Fernando Henrique Cardoso e Bill Clinton, além de tantos outros. No entanto, eliminar esses encontros seria comprometer um elemento central da memória das relações bilaterais construídas no Flickr a partir do governo Obama: o atual governo brasileiro. Um passeio pelo álbum revela que nada menos que dez das 19 fotografias do álbum possuem alguém da base aliada do então presidente Lula, geralmente ele próprio, mas, por vezes, seus ministros, e José Sarney, membro do PMDB e, à época, presidente do Senado. Pensando nas escolhas políticas no contexto de inauguração do governo Barack Obama, as publicações com Bush e Rice funcionam na rede social, dentro de uma memória majoritariamente democrata, para pôr em cena a atuação do então governo brasileiro. Assim, o álbum contempla a administração Lula antes da chegada de Obama, ao mesmo tempo em que diferencia aquela época da cordialidade e alegria que caracterizariam a parceria com o recémempossado democrata.

A quarta publicação do álbum segue o recuo ao governo Bush, na linha do tempo seguida pelo álbum, na segunda metade dos anos 2000. Dessa imagem, salta para um jantar oficial entre o presidente democrata Jimmy Carter e o presidente general Ernesto Geisel, em 1978 -imagem 3. As oito publicações do álbum que remontam a governos do século XX foram adicionadas a dois grupos - "História do Brasil" e "USA/Brasil" -, que somam poucos mais de 50 usuários no Flickr. Estas inserções sublinham um caráter histórico para as postagens no álbum. Como vimos, os encontros do democrata Bill Clinton com o presidente Fernando Henrique Cardoso nos anos 1990 não fazem parte da memória produzida no Flickr da embaixada norte-americana. Este lapso é compreensível dentro do conjunto de escolhas políticas do álbum se se pensar que, em 2009, o partido de FHC - o PSDB - fazia oposição ao governo chefiado pelo PT. Certamente não seria de 
bom tom a embaixada norte-americana memorar as boas relações que o partido democrata tinha com a atual oposição ao governo brasileiro, com o qual o recémempossado Obama começa a fazer contato.

A legenda desta publicação é uma das que oferecem menos informações no álbum. Explicita apenas o país, a data e o nome próprio das pessoas. É interessante perceber que esta legenda, lacônica, ignora que Geisel, além de presidente do Brasil, era também um general do exército. A não-inclusão de qualquer referência à Ditadura Militar na memória das relações bilaterais é compreensível se pensarmos que há pelo menos 20 anos no Brasil os partidos que ascendem ao governo federal se definem em oposição ao regime instaurado a partir do Golpe Civil-Militar de 1964. A publicação em questão se diferencia das demais também pelo formato da imagem. Enquanto as demais utilizam do padrão JPEG - que comporta até 16 milhões de cores -, até mesmo nas mais antigas, a quarta publicada está no formato GIF, de baixa qualidade visual. Ao jantar promovido pelo general para o presidente democrata, e sua esposa, foi destinada uma pequena imagem de cores saturadas. Nessa memória, construída na internet, os 21 anos de ditadura são abordados entre o silêncio e o esquecimento. Neste sentido, um personagem ausente se destaca: o democrata Lyndon B. Jonhson, que esteve na Casa Branca entre 1963 e 1969. Seu governo, sublinha Michel Weis (1993, p. 166), deu continuidade à montagem do Golpe de 1964, que derrubou João Goulart e alçou os militares ao poder no Brasil. Se a visita de Carter a Geisel em 1978 é um aspecto marginal nessa memória, as estreitas relações entre a ditadura e o governo de Lyndon Johnson é completamente apagada. 


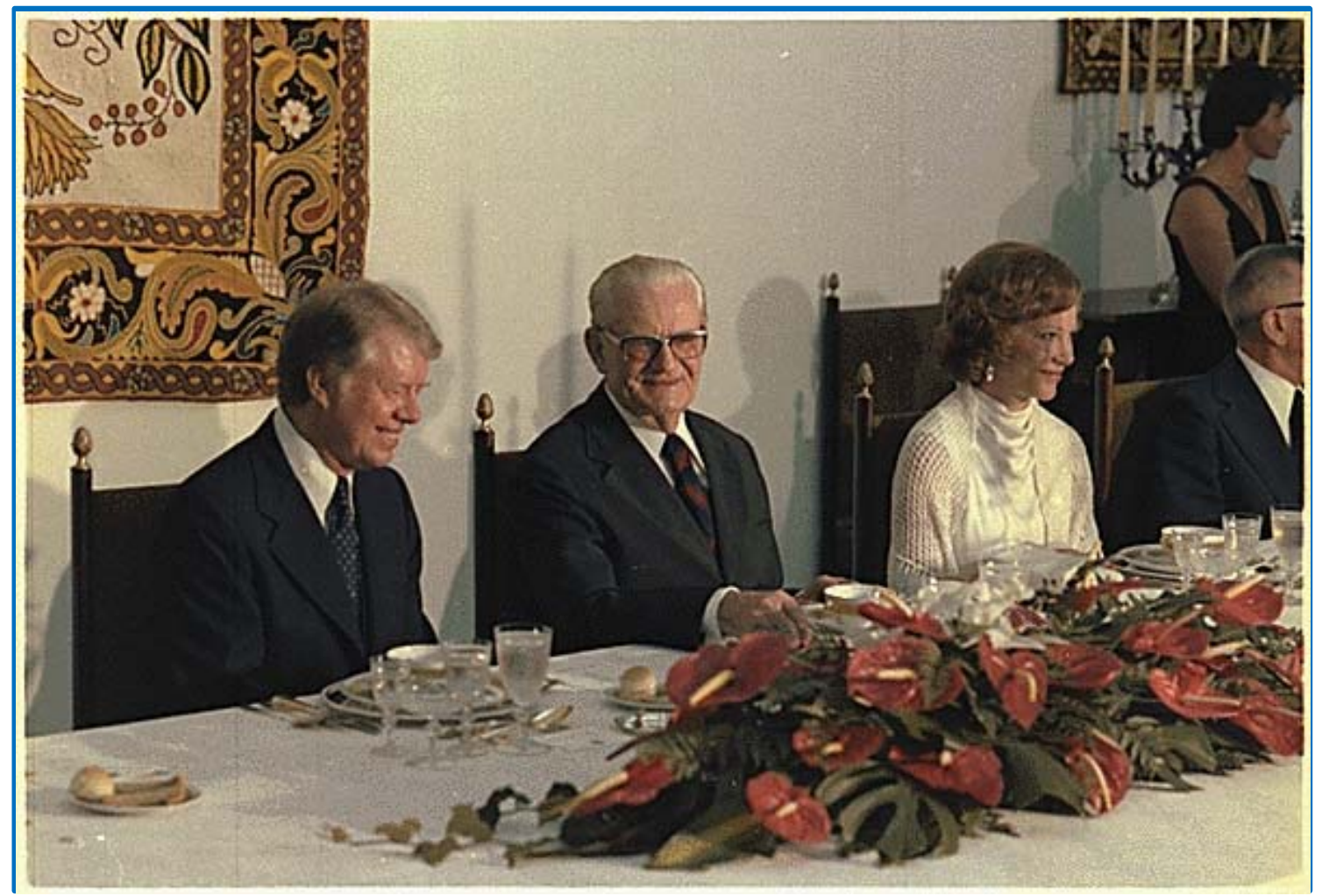

Imagem 3. Jantar oficial entre o democrata Carter e o general Geisel, única publicação do álbum que retoma a época da Ditadura Militar no Brasil ${ }^{9}$.

Já o seu antecessor ocupa um espaço central nas publicações - nada menos que cinco das 19 são destinadas ao presidente John F. Kennedy. Elas apresentam fotografias em preto e branco e informações detalhas sobre localização, datas, personagens e, por vezes, contextos. As duas primeiras são de abril de 1962; nelas, Kennedy e o presidente brasileiro João Goulart caminham enquanto conversam animadamente, acompanhados por um séquito de assessores, embaixadores e seguranças ${ }^{10}$.

As três outras são de 1961 e 1962 e trazem o presidente americano recebendo autoridades sul-americanas. Numa delas, temos o então embaixador do Brasil nos Estados Unidos, Roberto Oliveira Campos; noutra - a imagem 4 -, os ex-presidentes

\footnotetext{
${ }^{9}$ A fotografia faz parte do acervo da Casa Branca (fotógrafo e título original não identificados). A imagem foi convertida para o formato JPEG para atender às especificações da publicação. Disponível em <http://www.flickr.com/photos/embaixadaeua-brasil/3359342549/in/set-72157615306643483/> Acesso em: 17 mar. 2014.

${ }^{10}$ Todas as fotografias de John Kennedy pertencem ao acervo da Casa Branca e não possuem identificação do fotógrafo. Postagens disponíveis, respectivamente, nos seguintes endereços: <http://www.flickr.com/photos/embaixadaeua-brasil/3406980413/in/set-72157615306643483/>, <http://www.f lickr.com/photos/embaixadaeua-brasil/3407803796/in/set-72157615306643483/> Acesso em: 17 mar. 2014.
} 
Juscelino Kubitschek do Brasil e Lerras Camargo da Colômbia - e, por último, Celso Furtado, chefe da Superintendência para o Desenvolvimento do Nordeste (Sudene) ${ }^{11}$.

As imagens de energia, juventude, carisma e inteligência continuam a distinguir John F. Kennedy, mesmo depois de mais de cinquenta anos de sua morte. Ele foi constituído como mito no imaginário político norte-americano, como o que Cecília Azevedo (2007, p. 45) denomina de herói-presidente. Kennedy foi um dos presidentes que cativaram o público norte-americano, especialmente após sua morte, e sua imagem está associada, na América Latina, a programas como a Aliança para o Progresso e os Corpos de Paz. O trabalho de Henrique Alonso Pereira (2005, p. 26) coloca o Brasil como uma das prioridades da política externa do presidente democrata e o que mais recebeu atenção desses programas. Apesar de uma historiografia crítica do legado de Kennedy, que inclui, entre outros, o já citado Alonso Pereira e Noam Chomsky (1993), desnudar a imagem do herói da paz que promoveria o fim da Guerra do Vietnã se não tivesse sido assassinado, o mito persiste e é constantemente atualizado. As cinco publicações com ele, juntamente com as de Barack Obama, estão entre as mais vistas do álbum. Três delas ultrapassam as 1.500 visualizações. Quatro usuários adicionaram alguma das fotos às suas favoritas.

O presidente John Kennedy ocupa sempre o centro das fotografias e está geralmente sorrindo, em conversas amistosas com políticos e diplomatas. O presidente norte-americano é destacado também pela sua forma de vestir, como na imagem 4: ele aparece no álbum usando ternos claros e despojados - com a camisa à mostra enquanto os demais estão em trajes fechados e escuros. O conjunto de imagens de John F. Kennedy, utilizadas nessa memória das relações bilaterais, remete a um presidente jovem e de bom humor que se relaciona bem com os governantes e o corpo burocrático brasileiro. Também é de alguém que conhece os problemas brasileiros e é capaz de debatê-los com especialistas, como Celso Furtado. Os salões da Casa Branca, residência

\footnotetext{
${ }^{11}$ As postagens com o embaixador e o superintendente estão disponíveis respectivamente nos sítios eletrônicos <http://www.flickr.com/photos/embaixadaeua-brasil/3406941685/in/set72157615306643483/> e <http://www. flickr.com/photos/embaixadaeua-brasil/3407727886/in/set72157615306643483/> Acesso em: 17 mar 2014.
} 
oficial dos presidentes norte-americanos e símbolo do poder federal, surgem como o espaço onde acontecem esses amigáveis encontros bilaterais.

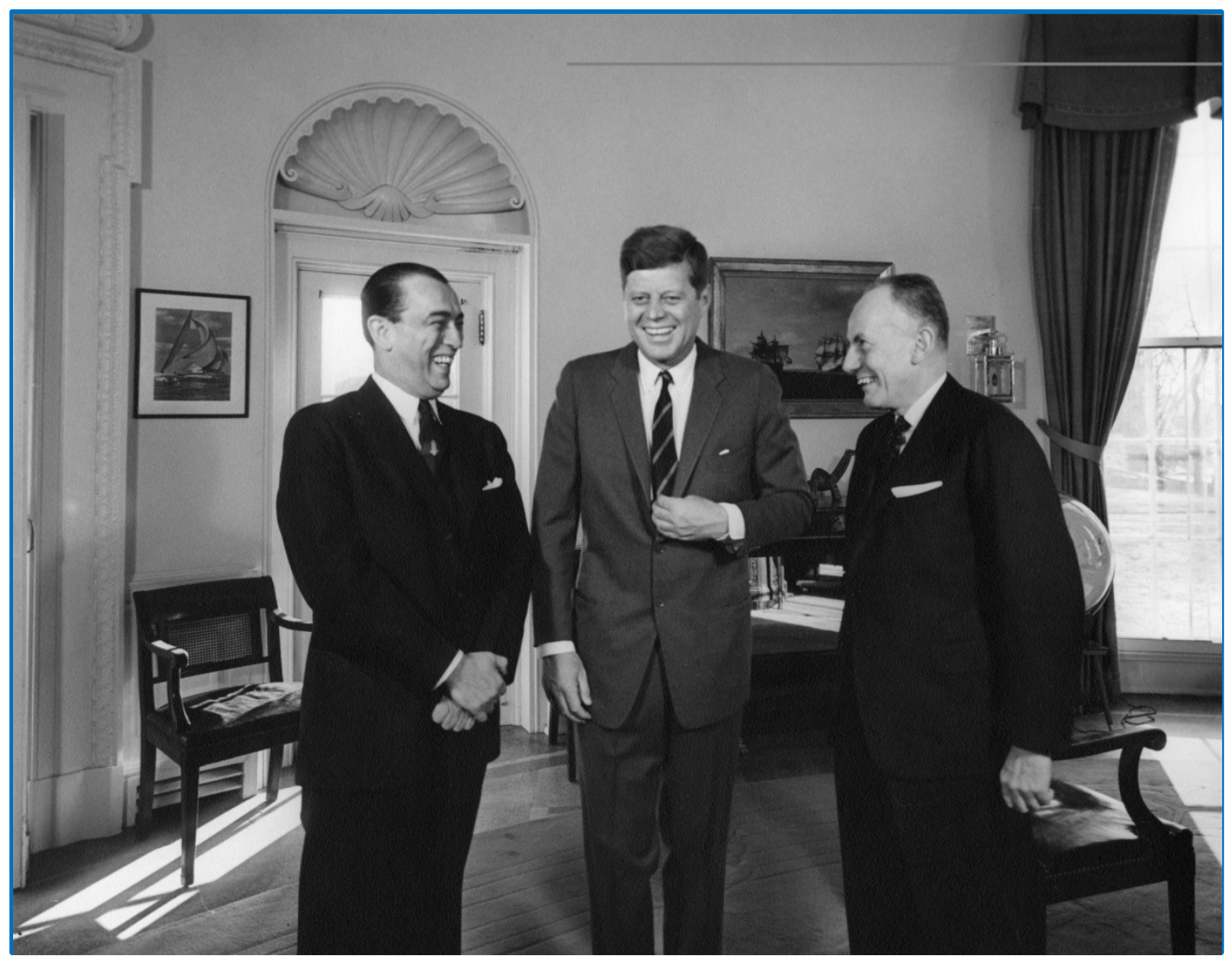

Imagem 4. O bem-humorado John F. Kennedy recebe os ex-presidentes Juscelino Kubitschek (Brasil) e Lerras Camargo (Colômbia) na Casa Branca em dezembro de $1962^{12}$.

Comparando as publicações do álbum com as fotos de Barack Obama, percebemos que essas e as de John F. Kennedy possuem diversas semelhanças. Como na imagem 1, e ainda outra do álbum ${ }^{13}$, Obama recepciona o presidente brasileiro em um dos salões de sua residência oficial. O estadunidense é apresentado como um líder jovem e carismático, que conversa com o presidente Lula no salão oval como se fossem amigos de longa data. Nas cinco fotografias selecionadas para compor o álbum em que Barack Obama está presente, ele está sempre com um sorriso; em duas delas, cumprimenta

\footnotetext{
${ }^{12}$ A publicação pode ser acessada no seguinte endereço eletrônico <http://www.flickr.com/photos/ embaixadaeua-brasil/3370436601/in/set-72157615306643483/> Acesso em: 17 mar. 2014.

13 Disponibilizada no seguinte endereço <http://www.flickr.com/photos/embaixadaeuabrasil/3488662198/in/set-72157615306643483> Acesso em: 17 mar. 2014.
} 
outras autoridades com um aperto de mão enquanto olha nos seus olhos. Assim como nas de Kennedy, o carisma é um componente central nas imagens de Obama publicadas para compor essa memória das relações bilaterais.

Depois das postagens com fotografias de John Kennedy, a série histórica sobre as relações bilaterais realiza um salto do começo dos anos 1960 para as décadas de 1940 e 1930 antes de voltar ao tempo presente. O álbum silencia os cerca de 15 anos entre a Segunda Guerra Mundial e a ascensão do herói-presidente em cujo governo o Brasil esteve distante das prioridades governamentais. Realizando uma abordagem global da política externa dos Estados Unidos, Cristina Pecequilo (2005, p. 218) avalia que o interesse estadunidense se deslocou para a reconstrução da Europa e ao combate ao comunismo no Velho Mundo, enquanto os países latino-americanos amargaram o fim da parceria que existia durante o período bélico. Neste período, não abordado no álbum, existiram dois encontros oficiais entre os presidentes Harry Truman, democrata que substituiu Roosevelt após sua morte, e Eurico Gaspar Dutra, em 1947 e 1949.

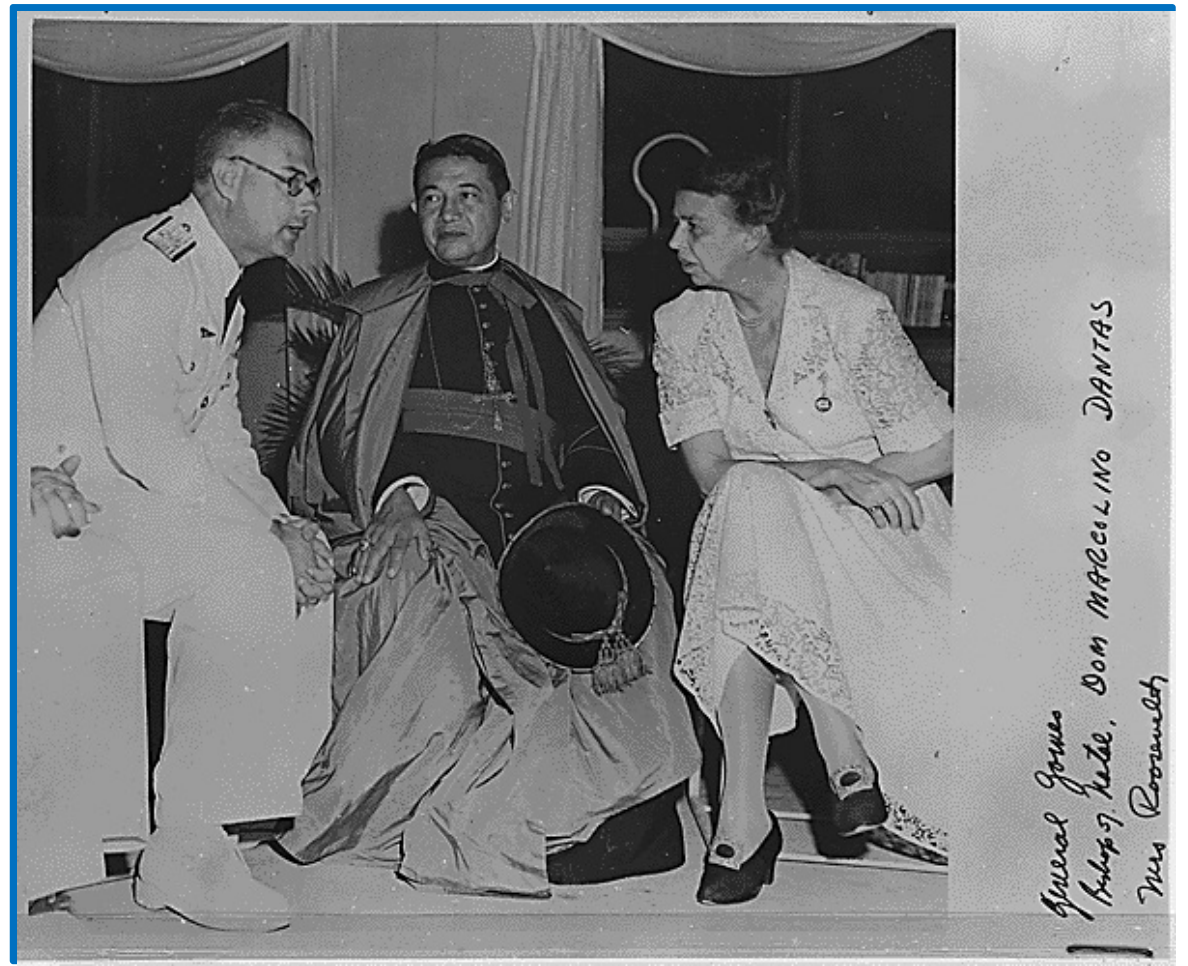

Imagem 5. Encontro entre a primeira-dama Eleanor Roosevelt, o brigadeiro Gomes e o bispo Dom Marcelino em Natal, Rio Grande do Norte ${ }^{14}$.

14 A publicação utiliza uma fotografia do acervo da Biblioteca Franklin Delano Roosevelt, sem autor identificado. Disponível em <http://www.flickr.com/photos/embaixadaeua-brasil/3359321441/in/set72157615306643483/> Acesso em: 17 mar 2014. 
É pertinente inquirir a respeito da escolha das fotografias para o recorte temporal das décadas de 1930 e 1940, pois nenhuma das duas trata diretamente da Segunda Guerra Mundial, evento em que comumente se identifica uma intensa parceria entre os Estados Unidos e o Brasil. As postagens não trazem qualquer informação sobre a data ou qualquer contexto para os encontros; apenas apresentam os personagens. A primeira é um jantar com os presidentes Getúlio Vargas e Franklin Delano Roosevelt ${ }^{15}$; a segunda imagem 5 -, da conversa entre o brigadeiro Eduardo Gomes, o bispo de Natal, dom Marcelino Dantas, e a primeira-dama Eleanor Roosevelt na capital do Rio Grande do Norte. A primeira postagem se aproxima de uma linha apresentada nas postagens anteriores: os presidentes estão sentados numa mesa de jantar e posam sorrindo para a foto. No segundo plano, uma série de personalidades não identificadas, de pé. Através de Pedro Tota (2000, p. 97), somos informados que se trata de uma parada de Roosevelt no Rio de Janeiro quando realizava uma viagem à Argentina, em 1936. Uma pesquisa no sítio eletrônico do National Archives ${ }^{16}$, acervo federal norte-americano, identifica que a segunda publicação é uma fotografia digitalizada de visita da primeira-dama em março de 1944, no contexto da Segunda Guerra Mundial. Esta é uma das duas postagens do álbum das quais saem de cena embaixadores e presidentes para dar lugar à primeira-dama, ao militar e ao bispo.

As escolhas das fotografias e o silêncio sobre o contexto delas nas postagens nos permitem pensar que, na memória das relações bilaterais produzida na rede social, não há espaço para as relações militares. A Segunda Guerra Mundial, por exemplo, não faz parte dessa memória. Não há também lugar para as ditaduras, como o Estado Novo.A ditadura chefiada por Getúlio Vargas entre 1937 e 1945 é silenciada, da mesma forma que a ditadura militar instaurada a partir de 1964. Entre as escolhas para a virada entre as décadas de 1930 e 1940, está uma fotografia produzida um ano antes do golpe de Estado e, outra, já durante o Estado Novo, da qual o ditador brasileiro e o presidente democrata

\footnotetext{
${ }^{15}$ Fotógrafo não identificado. A imagem pertence ao Acervo da Biblioteca Franklin Delano Roosevelt. A postagem pode ser visualizada em <http://www.flickr.com/photos/embaixadaeuabrasil/3360119258/in/set-72157615306643483/> Acesso em: 17 mar. 2014.

${ }^{16}$ Disponível em <http://research.archives.gov/description/195820> Acesso em: 17 mar. 2014.
} 
estão ausentes para dar vez ao diálogo da primeira-dama Eleanor Roosevelt com autoridades brasileiras.

A linha do tempo das relações bilaterais foi construída através das 11 primeiras postagens da primeira quinzena março de 2009. Nos meses seguintes, foram realizadas mais oito, que dão conta da atuação dos primeiros meses do governo Barack Obama. Entre o final de março e abril, quatro postagens de encontros internacionais foram adicionadas ao álbum das relações bilaterais. Nelas, o presidente norte-americano e seu vice aparecem juntamente com o presidente Lula em eventos diversos, com outros chefes de Estado. As quatro publicações foram adicionadas aos grupos "Flickr Central Brasil”, "Brasil/Brazil" e USA/Brasil", que somam cerca de 16 mil membros. Este grupos permitiram uma ampla divulgação entre os usuários da rede social. As fotos neles constantes estão entre algumas das mais visualizadas do álbum ${ }^{17}$.

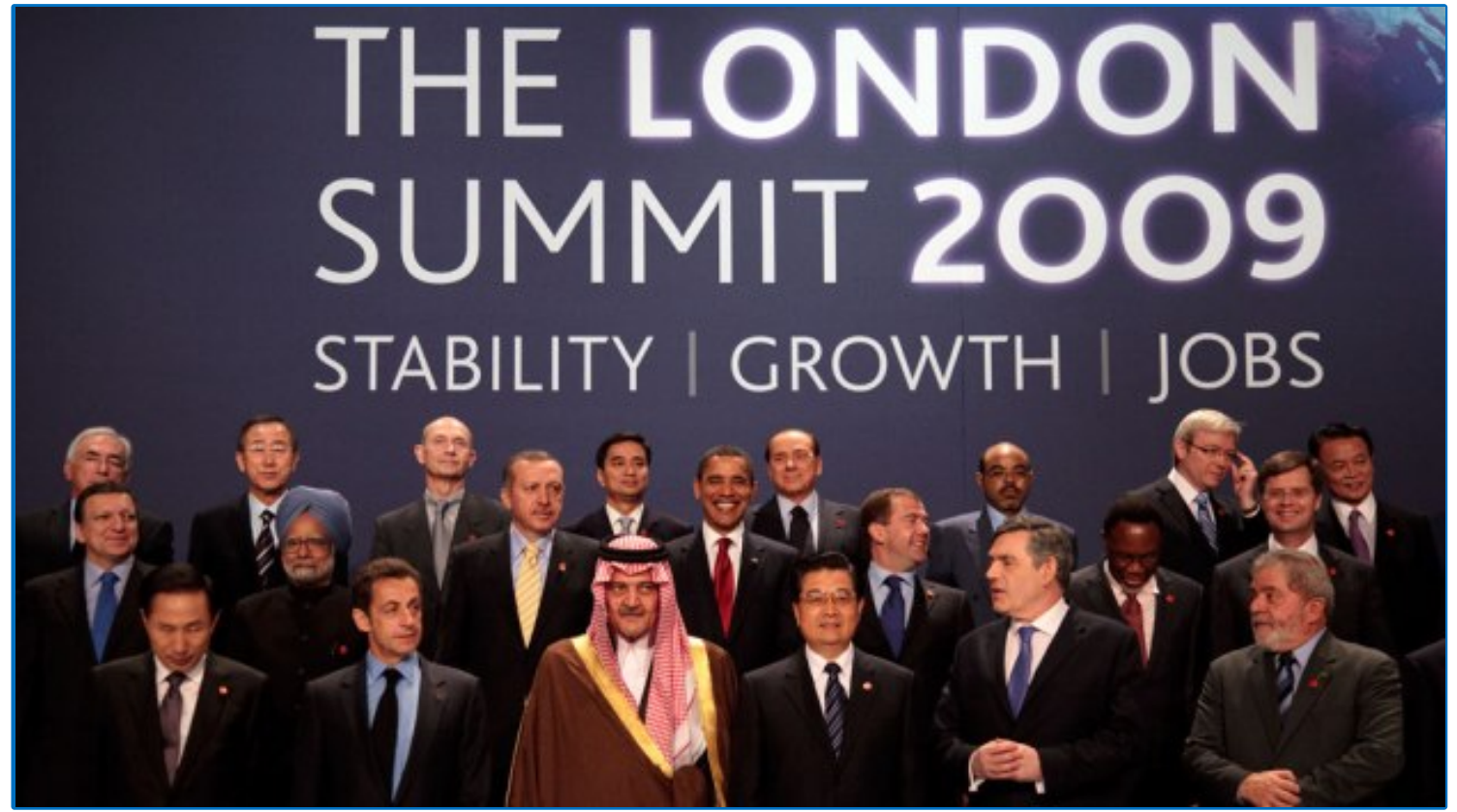

Imagem 6. Encontro em Londres do G-20, grupo formado por líderes de 19 países com as maiores economias mais a União Europeia ${ }^{18}$.

\footnotetext{
${ }^{17}$ As quatro postagens receberam, até então, respectivamente e por ordem de publicação, 2.395, 772, 729 e 1.310 visualizações.

${ }^{18}$ A fotografia utilizada na postagem faz parte do acervo da Casa Branca, possuíssem identificação do fotógrafo. A publicação no Flickr está disponível em <http://www.flickr.com/photos/embaixadaeuabrasil/3419012016/in/set-72157615306643483/> Acesso em: 17 mar. 2014.
} 
O primeiro desses encontros internacionais é o da Cúpula de Governança Progressiva, ocorrido em março de 2009 em Viña del Mar, no Chile. Nessa postagem, o vice-presidente democrata Joe Biden posa sorridente no centro da imagem, acompanhado de chefes de Estado do Brasil, Reino Unido, Noruega, Argentina, Espanha e Uruguai $^{19}$. O encontro seguinte a ser registrado é a reunião do G-20, em abril de 2009, em Londres. Nesta postagem -imagem 6 -, os presidentes do Brasil e dos Estados Unidos estão com os outros chefes de Estado, preparando-se para a foto oficial do evento. Barack Obama sorri, ao centro, rodeado dos líderes dos demais países; o presidente brasileiro está no canto inferior direito. A publicação no Flickr disponibilizou, entre outras ligações hipertextuais que se encontram indisponíveis para acesso, uma para uma postagem em inglês no blog da Casa Branca ${ }^{20}$. Nela é disponibilizado um vídeo com o discurso completo de Barack Obama durante o evento e alguns recortes textuais das falas do presidente norte-americano e do anfitrião do evento, o então primeiro-ministro britânico, Gordon Brown. Não há neles qualquer referência direta ao Brasil, mas ambos sublinham Barack Obama dissertando sobre os temas do encontro: empregos, crescimento e estabilidade.

As duas postagens seguintes são do quinto encontro da Cúpula das Américas, que aconteceu em Trindade e Tobago, também em abril de 2009. Na fotografia utilizada na primeira delas ${ }^{21}$, o presidente norte-americano ocupa novamente o centro, um pouco mais alto que os demais presidentes; Luiz Inácio Lula da Silva está no canto inferior esquerdo. Nessa publicação, o perfil da embaixada disponibilizou outra postagem de Jesse Lee, no blog da Casa Branca, que apresenta em vídeo e em texto trechos do discurso proferido por Obama no evento. Segundo Lee, em certo momento do discurso, o presidente estadunidense fez a seguinte avaliação das relações interamericanas:

\footnotetext{
${ }^{19}$ A publicação utiliza uma fotografia de autor e título não identificados, que pertence ao acervo da Casa Branca. Disponível em <http://www.flickr.com/photos/embaixadaeua-brasil/3418993944/in/set72157615306643483> Acesso em: 17 mar. 2014.

${ }^{20}$ Esta postagem no blog oficial do governo Obama está pode ser acessada em <http://www.whitehouse.gov/blog/o9/04/01/Morning-in-London/> Acesso em: 17 mar 2014.

21 Publicação disponível em <http://www.flickr.com/photos/embaixadaeua-brasil/3455878823/in/set72157615306643483/> Acesso em: 17 mar. 2014.
} 
Para seguir em frente, não podemos deixar-nos ser prisioneiros de desentendimentos passados. Estou muito grato que o presidente Ortega - (Aplausos) - Eu sou grato que o presidente Ortega não me culpe por coisas que aconteceram quando eu tinha três meses de idade (Risos). Muitas vezes, uma oportunidade para construir uma nova aliança das Américas tem sido minada por debates obsoletos. [...] Eu não vim aqui para debater o passado. Eu vim aqui para lidar com o futuro (Aplausos). Eu acredito que, como alguns dos nossos oradores afirmaram, que devemos aprender com a história, mas não podemos ser aprisionados por ela (LEE, 2009b) ${ }^{22}$.

O álbum sobre as relações bilaterais entre os Estados Unidos e o Brasil na História vai, de certa forma, no mesmo sentido do discurso de Barack Obama. Ao destinar mais da metade das postagens à administração do recém-empossado presidente democrata, a série procura, no mesmo passo, construir uma memória a partir de momentos-chave específicos do passado e afirmar a chegada de Obama como uma nova virada nas relações com o Brasil e os demais países do continente. A próxima publicação no Flickr - a da imagem 7 -, é também da Cúpula das Américas. Nela, Barack Obama e Oscar Arias, então presidente da Costa Rica, apertam a mão cordialmente sob supervisão do presidente brasileiro. No conjunto anterior de imagens, o Brasil é inserido, através da presença do presidente Lula, no palco das decisões globais e regionais. Nesta postagem, Lula ocupa o centro da imagem, observando o aperto de mãos entre o estadunidense e o costa-riquenho. O presidente brasileiro é inserido como intermediador das relações dos Estados Unidos com a América Latina.

\footnotetext{
22 "To move forward, we cannot let ourselves be prisoners of past disagreements. I am very grateful that President Ortega - (Applause) -- I'm grateful that President Ortega did not blame me for things that happened when I was three months old. (Laughter) Too often, an opportunity to build a fresh partnership of the Americas has been undermined by stale debates. [...] I didn't come here to debate the past -- I came here to deal with the future. (Applause.) I believe, as some of our previous speakers have stated, that we must learn from history, but we can't be trapped by it".
} 


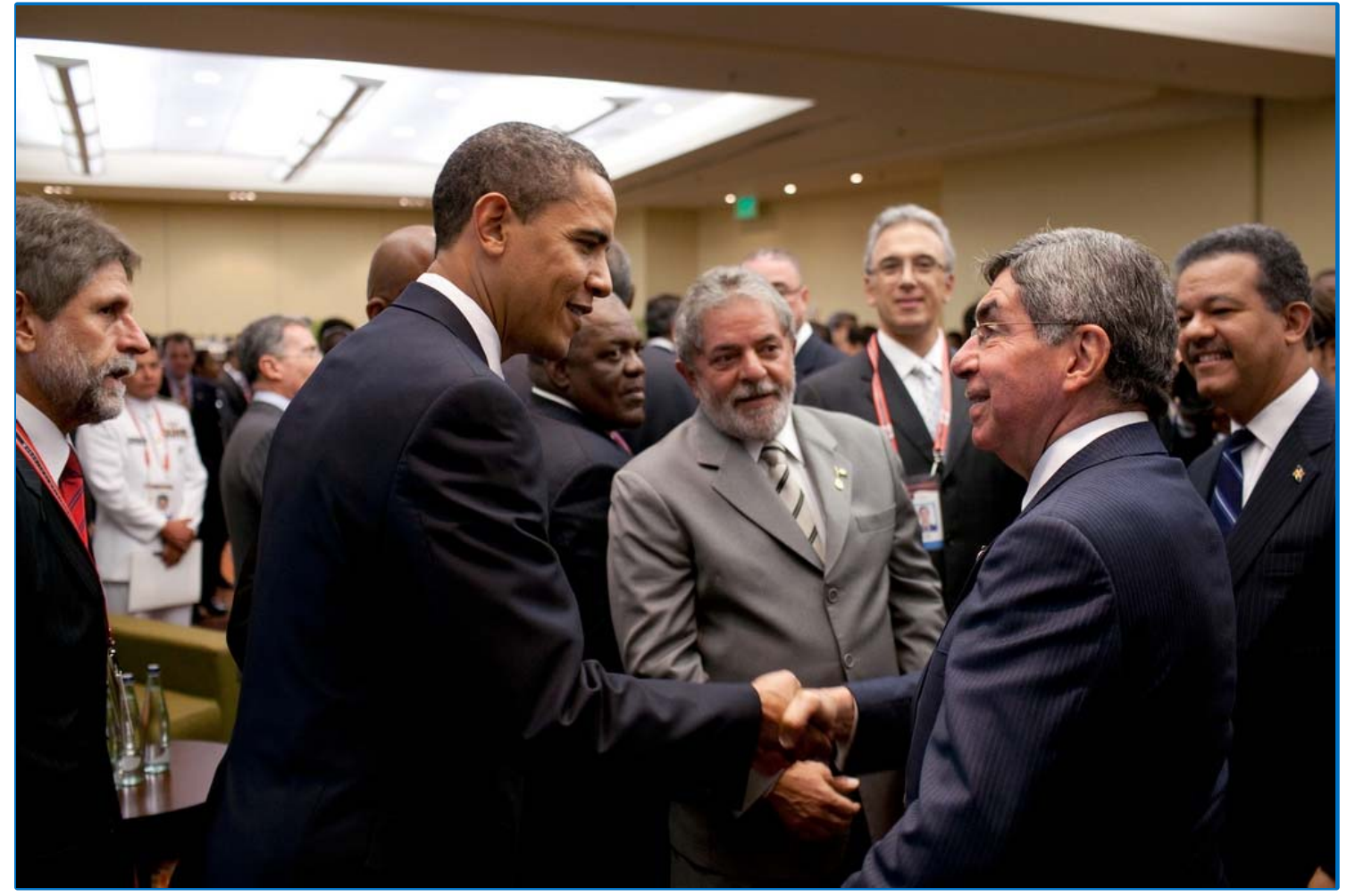

Imagem 7.Os presidentes Obama, Lula e Arias na Cúpula das Américas em Trindade e Tobago ${ }^{23}$.

As quatro postagens publicadas em sequência no Flickr, com seus respectivos textos e imagens, nos permitem pensar em uma visão específica das relações internacionais. Nelas, o representante norte-americano é a figura central, que referencia o posicionamento dos demais líderes. Ela afirma o novo governo como uma transformação do ator principal no cenário das decisões regionais e globais, os Estados Unidos. Ele agora buscaria esquecer os desentendimentos do passado para discutir com os demais países, de igual para igual, as ações a serem realizadas para desenvolver o continente. Estes posicionamentos não são exatamente uma novidade. Trabalhos como o de Lars Schoultz (2000) evidenciam que discursos de inauguração de um novo momento para as relações interamericanas, como o proferido por Obama, são recorrentes na política norte-americana há pelo menos cem anos. As postagens no Flickr da embaixada retomam indiretamente pelo menos dois desses momentos: os governos de Roosevelt (1933-1945) e Kennedy (1961-1963).

\footnotetext{
${ }^{23}$ Postagem disponível no endereço eletrônico a seguir <http://www.flickr.com/photos/embaixadaeuabrasil/348 5202617/in/set-72157615306643483/> Acesso em: 17 mar. 2014.
} 
Depois das publicações sobre os encontros internacionais, temos mais quatro postagens que fecham o álbum "Relações bilaterais na história”. A primeira delas ${ }^{24}$ é do mesmo contexto da capa do álbum: a visita do presidente brasileiro ao recém-empossado Barack Obama. Assim como a outra, esta imagem apresenta os presidentes em conversa cordial, dessa vez sentados no Salão Oval da Casa Branca, com seus respectivos tradutores. A próxima postagem trata do encontro de José Sarney, atualmente senador aliado do governo chefiado pelo PT, e Jimmy Carter, em Brasília, em maio de 2009. Na fotografia, os dois ex-presidentes conversam lado a lado em uma mesa de jantar. O expresidente democrata é apresentado no álbum em dois momentos, no que chamamos de linha do tempo das relações bilaterais e na atuação do governo Obama, em 2009, produzindo uma ideia de continuidade política da parceria entre o partido democrata e o Brasil. Este elo é reafirmado na publicação seguinte, que exibe uma fotografia do então ministro das relações exteriores do Brasil, Celso Amorim, e a secretária de Estado democrata, Hillary Clinton. Eles estão em um encontro bilateral no Departamento de Estado norte-americano em fevereiro de 2009. Posam em pé, entreolhando-se, cada um à frente da bandeira do próprio país ${ }^{25}$. As três postagens formam um conjunto em que representações governamentais equivalentes dos governos Lula e Obama dialogam, primeiro presidentes, depois ex-presidentes, e, por último, chefes da diplomacia.

A última postagem foi realizada no final de maio de 2009. É a única do álbum a apresentar a atuação de representantes da embaixada dos Estados Unidos no Brasil. Nela, crianças brasileiras do projeto "Educar Dançando" posam com sua professora e duas funcionárias da embaixada: Lisa Kubiske, encarregada de negócios, e Adele Ruppe, conselheira de educação, cultura e imprensa ${ }^{26}$. Esta fotografia é precursora do tipo de publicação mais comum no Flickr; é a primeira que apresenta uma ação da embaixada no Brasil. Em geral, as publicações na rede social envolvem eventos culturais e educacionais desenvolvidos pela embaixada americana tanto no Brasil como também nos Estados

\footnotetext{
${ }^{24}$ A postagem está disponível em <http://www.flickr.com/photos/embaixadaeua-brasil/3488662198/in/set72157615306643483/> Acesso 17 mar. 2014.

${ }^{25}$ A publicação apresenta uma fotografia de Jonathan Ernst do acervo da central de notícias Reuters. Disponível em <http://www.flickr.com/photos/embaixadaeua-brasil/3886608455/in/set72157615306643483/> Acesso em: 17 mar. 2014.

${ }^{26}$ Endereço eletrônico da postagem <http://www.flickr.com/photos/embaixadaeua-brasil/3588511761/in/set72157615306643483/> Acesso em: 17 mar. 2014
} 
Unidos. Há também alguns álbuns que fazem a cobertura fotográfica da visita de autoridades norte-americanas ao Brasil, como a visita do vice-presidente Joe Biden em maio de $2013^{27}$.

O perfil da embaixada dos Estados Unidos no Brasil continua até o presente realizando novas publicações, introduzindo novos personagens, temas e contextos ao seu acervo na internet. Ao realizar uma análise historiográfica de um dos seus álbuns, este trabalho investigou a produção de uma memória oficial das relações bilaterais com o Brasil, através das postagens na rede social Flickr, aproximando-nos, por este caminho, dos questionamentos da memória social para indagar o que a linguagem poética de Milan Kundera denomina de surpreendente aventura, na qual o narrador se apropria dos acontecimentos históricos. Identificamos, dessa forma, diversas configurações políticas que permeiam as estratégias de esquecimento e lembrança de variados encontros diplomáticas em momentos ao longo dos séculos XX e XXI.

A primeira delas é que se trata de uma memória amplamente democrata, que deixa pouquíssimos espaços para elementos republicanos. A segunda é uma memória atenta à situação política do Brasil, que afirma o governo petista de Lula enquanto esquece, por exemplo, a parceria com as duas administrações do presidente Fernando Henrique Cardoso (1995-2002) e os militares, instalados no poder a partir de 1964. Entre os esquecimentos, estão todos os momentos desde o final da década de 1930, quando, de alguma forma, o Brasil não constou das prioridades políticas norte-americanas, exceto nos anos finais do governo Roosevelt (1936-1945) e no breve governo Kennedy (19611963). Nessa memória não há espaços para os conflitos mundiais, como a Segunda Guerra Mundial e a Guerra Fria, apesar de esses eventos permearem boa parte das conjunturas da memória das relações bilaterais.

Através das imagens e textos das postagens, tomamos contato com a estratégia de se trabalhar com mitos consolidados na política norte-americana, como Abraham Lincoln e Jonh Kennedy, para afirmar um novo governo. Aliás, este é um componente

\footnotetext{
${ }^{27}$ O seguinte endereço eletrônico fornece todos os álbuns fotográficos postados pelo perfil da embaixada na rede social. <http://www.flickr.com/photos/embaixadaeua-brasil/sets/>. Para o álbum da visita de Biden ao Brasil ver <http://www.flickr.com/photos/embaixadaeua-brasil/sets/72157633833109615/> Acesso em: 17 mar. 2014.
} 
essencial dessa e de outras memórias políticas. Ela recupera os acontecimentos históricos de uma forma específica, que permite firmar um presente. Neste sentido, o Flickr da embaixada configura o passado para que o sorridente Barack Obama se apresente como uma novidade nas relações bilaterais, calcadas no que houve de melhor em tempos anteriores, para que Joe Biden, após sua visita oficial, tenha subido aos céus com lembranças de conversas amistosas e discursos elogiosos com as autoridades brasileiras.

\section{REFERÊNCIAS}

AZEVEDO, Cecília. Culturas políticas em confronto: a política externa norte-americana em questão. In: ENCONTRO DA ASSOCIAÇÃO NACIONAL DE PESQUISADORES DE HISTÓRIA LATINO AMERICANA E CARIBENHA, VI, Local do evento, 2004. Anais... Maringá: ANPHLAC, 2004.

AZEVEDO, Cecília. Em nome da América: os corpos de paz no Brasil. São Paulo: Alameda, 2007.

BURKE, Peter. Variedades de história cultural. Rio de Janeiro: Civilização Brasileira, 2000.

CHARTIER, Roger. A história ou a leitura do tempo. Belo Horizonte: Autêntica, 2009.

CHOMSKY, Noam. Camelot: os anos Kennedy. São Paulo: Scritta, 1993.

FELLET, João. Vice de Obama fecha visita ao país com afagos ao Brasil. In: BBC Brasil.[internet] São Paulo, 29 maio 2013. Disponível em <http://www.bbc.co.uk/portuguese/noticias/2013/05/130530_biden_mdb_jf.shtml> Acesso em: 17 mar. 2014.

FICO, Carlos. O grande irmão - da operação Brother Sam aos anos de chumbo: o governo dos Estados Unidos e a ditadura militar brasileira. Rio de Janeiro: Civilização Brasileira, 2008.

GIRARDET, Raoul. Mitos e mitologia políticos. São Paulo: Companhia das Letras, 1987.

GREEN, James; JONES, Abigail. Reinventando a história: Lincoln Gordon e as suas múltiplas versões de 1964.In: Revista Brasileira. História., v. 29, n. 57, p. 67-89, 2009.

KUNDERA, Milan. O livro do riso e do esquecimento. Rio de Janeiro: Nova Fronteira, 1987. 
LEE, Jesse. President Obama: a wonderful meeting of the minds. In: The White House Blog [Internet], Washington, 14 mar. 2009a. Disponível em

<http://www.whitehouse.gov/blog/09/03/14/president-obama-a-wonderful-meeting-ofthe-minds/> Acesso em: 17 mar. 2014.

LEE, Jesse. To learn from History, not be trapped by it. . In: The White House Blog [Internet], Washington, 18 abr. 2009b. Disponível em <http://www.whitehouse.gov/blog/09/04/18/To-Learn-from-History-Not-Be-Trapped-byIt/> Acesso em: 17 mar. 2014.

MAUAD, Ana Maria. Através da imagem: fotografia e história interfaces. Tempo, Rio de Janeiro, v. 1, n. 2, p. 73-98, 1996.

MAUAD, Ana Maria. Poses e flagrantes: ensaios sobre história e fotografia. Niterói: Editora UFF, 2008.

PECEQUILO, Cristina Soreanu. A política externa dos Estados Unidos. Porto Alegre: UFRGS, 2005.

PEREIRA, Henrique Alonso de A. R. Criar ilhas de sanidade: os Estados Unidos e a aliança para o progresso no Brasil. 2005. Tese (Doutorado) - Pontifícia Universidade Católica, São Paulo, 2005.

QUERO, Caio. No Rio, Biden diz que Brasil não é mais emergente e tem novas responsabilidades. In: BBC Brasil [internet], São Paulo, 29 maio, 2013. Disponível em <http://www.bbc.co.uk/portuguese/noticias/2013/05/130529_biden_no_rio_pai_cq.shtml> Acesso em: 17 mar. 2014

SCHOULTZ, Lars. Estados Unidos: poder e submissão: uma história da política norteamericana em relação à América Latina. Bauru: EDUSC, 2000.

WEIS, W Michael. Cold warriors and coups d'etat: Brazilian-American relations 1945-1964. Albuquerque: University of New Mexico Press, 1993. 
Recebido em 31/03/2014 Aprovado em 21/06/2014

Universidade do Estado de Santa Catarina - UDESC Programa de Pós-Graduação em História - PPGH

Revista Tempo e Argumento Volume 06 - Número 12 - Ano 2014 tempoeargumento@gmail.com 